\section{Os significados da "Sinfonia do café": uma releitura da canção de Humberto Teixeira}

\section{The meanings of the "Coffee Symphony:" a retelling of the song by Humberto Teixeira}

Francisco de Assis Guedes de Vasconcelos

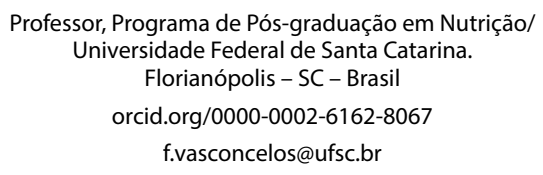

Recebido em 8 jun. 2017.

Aprovado em 28 maio 2018.
VASCONCELOS, Francisco de Assis Guedes de. Os significados da "Sinfonia do café": uma releitura da canção de Humberto Teixeira. História, Ciências, Saúde - Manguinhos, Rio de Janeiro, v.26, n.1, jan.-mar. 2019, p.145-163.

Resumo

$\mathrm{O}$ artigo toma como objeto central de investigação a letra da canção "Sinfonia do café", composta em 1944 por Humberto Teixeira, procurando analisála sob uma perspectiva sócio-histórica e linguística. A análise buscou suporte teórico na filosofia da linguagem de Mikhail Bakhtin, em particular, suas concepções de "enunciação" e "interação verbal". A partir da relação intersubjetiva entre locutor e interlocutor, buscamos identificar possíveis significações da canção e do tema central abordado (café) no contexto de sua criação. A análise evidenciou a função político-ideológica que o gênero musical samba-exaltação exerceu no Estado Novo. Naquele contexto, café e samba-exaltação foram os principais produtos de exportação (agrícola e musical) que deveriam expressar a grandiosidade econômica e cultural brasileira.

Palavras-chave: café; samba-exaltação; música popular brasileira; Humberto Teixeira (1915-1979); Mikhail Bakhtin (1895-1975).

\section{Abstract}

This article focuses on the lyrics of "Sinfonia do café" ("Coffee Symphony"), a song composed in 1944 by Humberto Teixeira, and attempts to analyze it from a linguistic and socio-historical perspective. The theoretical foundation of this analysis is Mikhail Bakhtin's philosophy of language, particularly his understanding of enunciation and verbal interaction. Based on the intersubjective relationship between speaker and interlocutor, we look for potential meanings in this composition and the main topic (coffee) within the context of its creation. This analysis shows the role played by the musical genre known as samba-exaltação during the New State period. Within this context, coffee and samba-exaltação were the main exports (agricultural and musical) that were intended to express the splendor of Brazilian economics and culture.

Keywords: coffee; samba-exaltação; Brazilian popular music; Humberto Teixeira (19151979); Mikhail Bakhtin (1895-1975). 
$\mathrm{E}$ ste artigo é um ensaio de natureza descritivo-qualitativa, que toma como objeto central de investigação a letra da canção "Sinfonia do café", composta em 1944 por Humberto Teixeira (1915-1979) (Teixeira, 2002), procurando analisá-la dentro de uma perspectiva sócio-histórica (ou contextual) e linguística. A análise da canção buscou suporte teórico na filosofia da linguagem de Mikhail Bakhtin (1999), em particular, suas concepções de "enunciação" e "interação verbal". A partir da complexa relação intersubjetiva entre locutor (autor/compositor) e interlocutor (ouvinte/espectador/leitor/telespectador), buscamos identificar possíveis significações da canção e do tema central abordado (café) no contexto de sua criação.

No campo da análise da música popular brasileira (MPB), em breve levantamento bibliográfico dos artigos publicados nos últimos dez anos na Scientific Electronic Library Online (Scielo), observamos que os caminhos metodológicos são múltiplos, sendo utilizadas, entre outras, abordagens musicais ou musicológicas (Assis, 2009; Côrtes, 2014); de performance musical (Falbo, 2010; Noleto, 2014); etnomusicológicas ou antropológicas (Baraldi, 2016; Brilhante, Nations, Catrib, 2018); sócio-históricas ou contextuais (Garcia, 2011; Costa, 2015), linguísticas (Freitas, Facin, 2012; Mori, 2015) e interdisciplinares ou mistas (Motta, 2015; Ernica, Molina, 2016).

As abordagens musicológicas consistem em estudos das composições musicais em si, a partir da análise de suas formas harmônicas, melódicas e estruturais. Em geral, são restritas aos pesquisadores e profissionais do campo da música, caracterizando-se pela investigação de elementos técnico-musicais, tais como melodia, harmonia, ritmo, sonoridade (altura, timbre, intensidade e duração do som), estrutura, textura e estilo da composição musical. Como exemplo, apontamos o estudo realizado por Assis (2009), pianista, compositor e pesquisador, cuja análise da composição "Choros n.5 - Alma brasileira", de Heitor Villa-Lobos (1887-1959), teve como foco uma abordagem dos planos formal, harmônico, rítmico e melódico e sua relação com elementos da retórica, a partir do conceito de figuras musicais.

As análises categorizadas como performance musical têm como eixo orientador da investigação a performance da canção (palavra, texto ou poesia cantada), ou seja, o conjunto de interações que se estabelece entre o corpo do locutor (cantor, intérprete, músico), notadamente sua voz (bem como indumentárias, gestos e movimentos), e seus interlocutores (o público) no momento da sua ocorrência, seja essa performance realizada de forma presencial ou mediatizada. Como ilustração, referimos o estudo de Noleto (2014), o qual teve como objetivo discutir a performance musical - vocal e corporal - da cantora Gal Costa, dentro do movimento estético denominado tropicalismo, a partir da imbricação de conceitos pertinentes à música, à antropologia e aos estudos de gênero e sexualidade.

Os estudos etnomusicológicos, em geral, apresentam características de investigações etnográficas, utilizando-se de referenciais teóricos das ciências sociais e humanas, notadamente antropologia e sociologia. Um exemplo é o estudo de Brilhante, Nations e Catrib (2018), que buscou compreender os sentidos atribuídos à violência sexual contra a mulher expressa nas letras de forró por rapazes adolescentes residentes na periferia de Fortaleza (CE). De acordo com Brilhante, Nations e Catrib (2018), a etnomusicologia considera que estudos de músicas regionais e suas performances transpõem o espaço 
geográfico de sua execução, na medida em que descortinam práticas universalmente disseminadas de legitimação de violências.

Os estudos com abordagens sócio-históricas, em geral, são investigações sobre as relações estabelecidas entre a obra musical e o espaço social, histórico ou contextual de sua criação ou execução. Um exemplo característico é o estudo de Costa (2015), que buscou reconstruir o percurso histórico da transformação do carimbó como expressão típica da musicalidade cabocla do Pará e da Amazônia, a partir da análise dos debates entre folcloristas, jornalistas e escritores nos anos 1900-1960.

Nas abordagens linguísticas, em geral, o foco central do estudo é a letra da canção, usando-se distintos enfoques teóricos e procedimentos técnicos. Nessa modalidade, tomando como objeto de estudo a letra da música "Canto para minha morte", composta em 1976 por Raul Seixas (1945-1989), Freitas e Facin (2012) buscaram analisar o sentido linguístico de morte que se depreende da relação intersubjetiva entre o locutor e o interlocutor, a partir da teoria da enunciação de Émile Benveniste (1902-1976).

As abordagens interdisciplinares, em geral, caracterizam-se pelo uso de dois ou mais tipos de análises. Nessa direção, tendo como objeto de investigação o samba "Portela na avenida", composto pela dupla Mauro Duarte (1930-1989) e Paulo César Pinheiro (1949- ), popularizado na gravação de Clara Nunes (1942-1983), o estudo de Ernica e Molina (2016) procurou realizar uma análise da composição a partir da articulação entre abordagens dos tipos sócio-histórica, musical e linguístico discursiva.

No levantamento bibliográfico realizado, nenhuma publicação sobre Humberto Teixeira e o samba-exaltação "Sinfonia do café" foi capturada, denotando a escassez ou inexistência de estudos científicos publicados sobre a trajetória desse compositor e sua contribuição para a MPB e justificando a pertinência do presente artigo.

\section{Sobre o método e as fontes da investigação}

No percurso metodológico para análise dos possíveis significados de "Sinfonia do café", tomamos como referencial teórico as concepções de "enunciação" e "interação verbal" utilizadas na filosofia da linguagem de Bakhtin (1999).

O objeto da investigação, a canção "Sinfonia do café", será concebido como um instrumento de "interação verbal" entre o compositor Humberto Teixeira (locutor) e seus distintos interlocutores. A investigação parte do pressuposto bakhtiniano de que a obra estabelece

vínculos com o conteúdo total da consciência dos indivíduos receptores e só é apreendida no contexto dessa consciência que lhe é contemporânea. A obra é interpretada no espírito desse conteúdo da consciência (dos indivíduos receptores) e recebe dela uma nova luz. É nisso que reside a vida da obra ideológica. Em cada época de sua existência histórica, a obra é levada a estabelecer contatos estreitos com a ideologia cambiante do cotidiano, a impregnar-se dela, a alimentar-se da seiva nova secretada (Bakhtin, 1999, p.119).

Partimos do pressuposto que a análise da canção popular como objeto semiótico ou produto da interação verbal entre locutor e interlocutor deve ser feita levando em consideração 
a interligação de suas estruturas musicais, verbais e não verbais (ou performáticas). Nesse sentido, também compartilhamos da concepção de que a comunicação verbal se entrelaça aos outros tipos de comunicação e cresce com eles sobre o terreno comum da situação de produção. Para Bakhtin (1999, p.124), “a comunicação verbal é sempre acompanhada por atos sociais de caráter não verbal (gestos do trabalho, atos simbólicos de um ritual, cerimônias etc.), dos quais ela é muitas vezes apenas o complemento, desempenhando um papel meramente auxiliar". Entretanto, neste artigo, nos limitaremos apenas à análise de aspectos da estrutura verbal da canção.

Sobre as fontes da investigação, cabe explicitar alguns procedimentos metodológicos que nos guiaram. Em primeiro lugar, ressaltamos que, em função do não acesso à fonte primária de gravação da canção "Sinfonia do café", optou-se por usar como referência bibliográfica a sua regravação pela cantora Rita Ribeiro no ano de 2002 (Teixeira, 2002). De forma análoga, procedeu-se com as canções "Asa branca" e "Assum preto", também regravadas em 2002, em show-tributo a Humberto Teixeira, pelas cantoras Maria Bethânia e Elba Ramalho (Teixeira, Gonzaga, 2002a, 2002b). É importante destacar que a releitura das letras das referidas composições foram realizadas a partir de reprodução de suas letras originais. Entretanto, a "escuta/audição" das canções foi realizada a partir de regravações feitas no ano de 2002 e também das gravações originais, usando os recursos disponíveis atualmente na internet (vídeos, documentários com gravações sonoras do período). Nesse sentido, descarta-se a possibilidade do ouvinte/leitor contemporâneo, que não vivenciou a escuta/leitura das canções no contexto histórico de suas gravações originais, imprimir nessa leitura contemporânea sentimentos, emoções e interpretações tais quais aqueles vivenciados pelos ouvintes/leitores dos contextos de criação original dessas canções.

Na tentativa de fundamentar a escolha do objeto, tema e procedimentos metodológicos, realizou-se levantamento bibliográfico sistematizado na base Scielo, utilizando-se os unitermos música, música popular brasileira, MPB, samba, samba-exaltação, baião, história da música brasileira, crítica musical, Humberto Teixeira e Luiz Gonzaga, tanto de forma isolada, como associando dois ou mais deles. Ao utilizar o unitermo música de maneira isolada, observou-se uma vasta produção de artigos científicos publicados $(\mathrm{n}=435)$, ao passo que, para outros unitermos isolados, a produção de artigos é bem mais reduzida ou inexistente: música popular $(n=35)$, samba $(n=41), \operatorname{MPB}(n=11)$, baião $(\mathrm{n}=2)$, história da música brasileira $(\mathrm{n}=1)$, crítica musical $(\mathrm{n}=1)$, Luiz Gonzaga $(\mathrm{n}=2)$, samba-exaltação $(n=0)$ e Humberto Teixeira $(n=0)$.

Como suporte instrumental do estudo, foram realizadas ainda buscas assistemáticas da literatura sobre as temáticas análise da música popular brasileira, história do café no Brasil e biografia de Humberto Teixeira em distintos endereços/sítios eletrônicos de dados.

\section{O "doutor do baião": síntese biográfica comentada de Humberto Teixeira}

Humberto Cavalcanti Teixeira nasceu no dia 5 de janeiro de 1915, no município de Iguatu (CE). Sua inclinação para a música ocorreu desde a infância, quando aprendeu a tocar gaita de foles, flauta e bandolim. Em 1928, aos 13 anos, editou sua primeira composição e tocava flauta na Orquestra Iracema, que musicava os filmes mudos no Cine Majestic, em 
Fortaleza. Em 1930, migrou para o Rio de Janeiro. Em 1944, formou-se em ciências jurídicas e sociais pela Faculdade Nacional de Direito da atual Universidade Federal do Rio de Janeiro (Marcondes, 1977; FGV, 2001; O homem..., 2008; ICCA, s.d.-b).

Na sua trajetória em busca de inserção, percorreu os distintos gêneros musicais que caracterizaram a cena musical carioca nas décadas de 1930 e 1940. À época, em parceria com Lauro Maia ${ }^{1}$ (1913-1950), já tinha composto sambas, sambas-canções, marchas, xotes, toadas e tentava lançar o ritmo nordestino balanceio. Em 1944, em parceria com o maestro Lirio Panicalli (1906-1984), gravou o samba "Sinfonia do café", cantado por Deo (Ferjalla Rizkalla) (1914-1971) e o Coro dos Apiacás, com acompanhamento da orquestra Napoleão Tavares e seus Soldados Musicais (Marcondes, 1977; FGV, 2001; O homem..., 2008; Programa Perfil, 2015; ICCA, s.d.-a, s.d.-b).

Nesse contexto da gravação de "Sinfonia do café", é interessante observar a complexa rede de locutores e de recursos instrumentais que o autor principal da canção utilizou. Aqui queremos chamar a atenção para o envolvimento do próprio autor principal (advogado, músico, compositor profissional que buscava "afirmação" no cenário musical), de um músico profissional como coautor da composição musical (maestro e compositor profissional já consagrado no cenário musical carioca e brasileiro desde a década de 1920), um intérprete profissional (cantor e compositor profissional já consagrado no cenário musical desde meados da década de 1930), um coral infantojuvenil profissional (criado em meados da década de 1930, com participações em gravações de disco e programas de rádio desde 19351936) e uma orquestra profissional (orquestra dirigida pelo maestro e compositor Napoleão Tavares, com gravações de discos e participações em programas de rádio desde 1935). À época, todos esses sujeitos participantes da gravação da canção estavam envolvidos com o disco, o rádio e o teatro musicado, canais de veiculação da música popular brasileira (Marcondes, 1977; ICCA, 2018).

Segundo o depoimento de Humberto Teixeira (O homem..., 2008), as tentativas sem êxito em busca de cantores famosos como Orlando Silva (1915-1978), Carmen Miranda (1909-1955) e Dalva de Oliveira (1917-1972) para gravação de suas canções foram inúmeras. Em 1944, entretanto, recebeu o convite para musicar o espetáculo teatral "Muiraquitã, talismã do Brasil". Compôs para o espetáculo "Sinfonia do café", que seria sua primeira canção a ser gravada: "Até que um dia veio a primeira gravação - 'Sinfonia do café'. Foi um sucesso enorme, não só a peça no Municipal de São Paulo, como no Municipal do Rio, mas para a minha própria música. E aí começou outra história fabulosa..." (O homem..., 2008).

Essa narrativa do compositor explicitando os possíveis motivos de "inspiração" para a obra musical torna-se de fundamental relevância para a análise de sua significação. A relação entre a música popular, o teatro musicado (de revista), o rádio e o cinema no Brasil tem sido identificada como um fenômeno contemporâneo ao próprio nascimento do gênero samba em meados da década de 1910 (Tinhorão, 2013). No caso de Humberto Teixeira ter sido convidado a musicar a referida peça teatral, a canção criada, tanto em termos de melodia como de letra, pode ter relação com a temática da peça teatral, com possíveis exigências de quem o convidou, com as normas e regulamentos dos órgãos de censura da época e tantos outros fatores contextuais e subjetivo-pessoais que impulsionaram a sua inspiração. Entretanto, neste ponto da análise, queremos enfatizar apenas a vinculação 
entre a criação de "Sinfonia do café" e a referida peça teatral, meio ou canal imediato de realização social dessa canção.

Acompanhando a trajetória de Humberto Teixeira, observamos divergências na afirmação de que "Sinfonia do café" teria sido a sua primeira composição gravada. Talvez tenha sido o seu primeiro sucesso de público, pois identificamos referências que relatam gravações anteriores de composições de sua autoria em disco de 78 rotações (78rpm): a marcha "Dona Santa não é santa" (1941), o samba "Altiva América" (1942), a marcha "Racionamento" (1942) e a marcha "Pelo Brasil, pela vitória" (1943) (Vivacqua, 2004; Programa Perfil, 2015).

Na trajetória musical desse compositor, vale destacar sua passagem pela composição de canções abordando a temática da guerra, fase na qual a relação entre o tema central da composição e o contexto histórico de sua inspiração parece bem evidente. Como exemplos de canções alusivas à Segunda Guerra Mundial de sua autoria se destacam o samba "Altiva América" (1942), a marcha "Racionamento" (1942) e a marcha "Pelo Brasil, pela vitória" (1943) (Vivacqua, 2004). Sobre esta última composição, Humberto Teixeira, em entrevista concedida ao pesquisador cearense Miguel Ângelo de Azevedo, em 11 de dezembro de 1977, fez a seguinte observação: "uma marcha apoteótica, estilo guerreiro e coisa, conclamando os nossos irmãos para a luta [aderirem à Força Expedicionária Brasileira] - uma barbaridade dessas que eu não faria hoje". É preciso destacar que o uso do tema da Segunda Guerra Mundial não foi privilégio desse autor, outros compositores que foram seus contemporâneos também transitaram por essa temática. Aliás, esse tema já tinha feito parte do repertório musical de compositores brasileiros desde o contexto da Primeira Guerra Mundial (O homem..., 2008; Programa Perfil, 2015; Fagundes, 2017).

Em 1945, seus sambas "Só uma louca não vê" e "Samba da roça", ambos em parceria com Lauro Maia, foram gravados pelo cantor Orlando Silva, conhecido como o "cantor das multidões". Neste mesmo ano teve início a parceria com Luiz Gonzaga, dupla que tornou o baião - ritmo musical nordestino - nacional e internacionalmente conhecido e valorizado. Nos anos 1950, 1951 e 1952 foi eleito o "melhor compositor nacional" pela Revista do Rádio, sendo recebido no palácio do Catete pelo presidente Getúlio Vargas (FGV, 2001; O homem..., 2008; ICCA, s.d.-b).

Em 1954, teve início sua trajetória no campo da política partidária, quando se candidatou a deputado federal pelo Ceará na legenda do Partido Social Progressista (PSP), partido considerado de tendência política de centro-esquerda. Ao longo da legislatura 1955-1958, exerceu o mandato em quatro ocasiões, na qualidade de suplente. Na oportunidade, destacou-se pela defesa dos direitos autorais dos compositores musicais, obtendo a aprovação da Lei Humberto Teixeira, que permitiu a realização de caravanas para a divulgação da música popular brasileira no exterior. Candidatou-se à reeleição em 1958, mas não foi reeleito (FGV, 2001; O homem..., 2008; ICCA, s.d.-b).

Entre 1957 e março de 1964, participou de várias caravanas para divulgação da música popular brasileira no exterior (Inglaterra, França, Portugal, Espanha, Itália, Noruega). A parceria com Luiz Gonzaga parece ter sido interrompida por ocasião do mandato político eleitoral; entretanto, Luiz Gonzaga continuou a gravar suas canções até 1979 (FGV, 2001; O homem..., 2008; ICCA, s.d.-b). 
Possivelmente, por sua formação em ciências jurídicas e sociais, o cognome "doutor do baião" foi dado pelo parceiro Luiz Gonzaga, conhecido por "rei do baião" (FGV, 2001; O homem..., 2008; ICCA, s.d.-b).

Humberto Teixeira compôs mais de quatrocentas canções, ${ }^{2}$ sendo as mais difundidas interpretadas por Luiz Gonzaga. Muitos artistas gravaram e continuam revisitando suas composições, ${ }^{3}$ fato que atesta a relevância e a atualidade delas (FGV, 2001; O homem..., 2008; ICCA, s.d.-b).

Em 3 de outubro de 1979, aos 64 anos de idade, faleceu de enfarte do miocárdio, em São Conrado, no Rio de Janeiro. Em 27 de agosto de 2002, foi realizado no Teatro Rival, no Rio de Janeiro, um show-tributo em sua memória, que resultou numa gravação ao vivo de um CD com 17 composições de sua autoria, entre elas "Asa branca", "Assum preto" e "Sinfonia do café", interpretadas por diversos cantores da MPB contemporânea, evento que reafirma o importante papel de suas composições na história da música brasileira (FGV, 2001; O homem..., 2008; ICCA, s.d.-b).

\section{A "Sinfonia do café": uma tentativa de releitura da canção}

Ao ouvir a canção, a interpretação inicial é que ela se enquadra no gênero musical sambaexaltação, estilo de samba cuja característica principal seria a exaltação das qualidades e da grandiosidade do país. O samba-exaltação, samba cívico ou samba patriótico, foi uma modalidade de música estimulada pelo Estado Novo (1937-1945), caracterizada por melodia extensa, letra abordando temática nacionalista ou patriótica, ampla utilização de instrumentos musicais de metal, arranjos orquestrais e recursos sinfônicos. Foi um gênero musical cultivado por compositores profissionais vinculados ao teatro musicado, ao rádio e às gravadoras de disco a partir de meados da década de 1930. Para distintos autores, teve como "exemplo paradigmático" a canção "Aquarela do Brasil", composta em 1939 por Ary Barroso (1903-1964) (Marcondes, 1977; Paranhos, 2003; Cunha, 2004; Fenerick, 2005; Furtado Filho, 2009; Farias, 2014).

Vale destacar que, à época da primeira gravação de "Sinfonia do café", conforme apontam distintas análises, o gênero musical samba - que teria emergido e se propagado entre meados dos anos 1910 e 1930 como padrão de música urbana brasileira, sobretudo no Rio de Janeiro - já havia rompido as fronteiras geográficas e sociais de sua origem. Para além dos morros cariocas, nas primeiras décadas do século XX, o samba já havia iniciado a sua trajetória de disseminação para transformação em produto cultural brasileiro. Distintas modalidades e estilos de sambas - samba-canção, samba-choro, samba de breque, samba de carnaval, samba-enredo - transitavam nesse cenário até a emergência do gênero samba-exaltação (Marcondes, 1977; Napolitano, Wasserman, 2000; Paranhos, 2003; Cunha, 2004; Fenerick, 2005; Furtado Filho, 2009; Tinhorão, 2013; Farias, 2014).

Os indícios do uso político-ideológico do samba-exaltação como instrumento de legitimidade do Estado Novo são frequentes e fortemente evidenciados nas distintas análises sobre a MPB difundida nas décadas de 1930 e 1940 (Napolitano, Wasserman, 2000; Paranhos, 2003; Cunha, 2004; Fenerick, 2005; Furtado Filho, 2009; Farias, 2014). Em geral, os vestígios dessa associação são relacionados à atuação do Departamento de 
Imprensa e Propaganda (DIP), órgão criado por Vargas em 1939, embora já existisse com outros nomes e funções similares desde 1931. Em sua vigência no período de 1939-1945, o DIP constituiu um aparelho de Estado para controlar e orientar a propaganda, abrangendo imprensa, literatura, cinema, teatro, esporte, recreação, radiodifusão, música e quaisquer formas de manifestação cultural (Alencar, Ramalho, Ribeiro, 1996; Paranhos, 2003; Cunha, 2004; Fenerick, 2005; Furtado Filho, 2009).

No cenário musical e, particularmente, no terreno do samba carioca, a literatura evidencia que a política cultural do Estado Novo buscou censurar elementos do samba que remetessem às características de suas raízes étnicas, geográficas e sociais, consideradas indesejáveis e inadequadas aos olhos dos censores, bem como impor o caráter histórico, didático e patriótico que as composições deveriam ter. Nesse sentido, o samba-exaltação seria a versão idealizada da música brasileira que o Estado Novo forjou projetar para o Brasil e para o mundo como símbolo de nossa identidade musical. Assim como o café (tema central da canção analisada) era o produto agrícola que expressava, naquele contexto, a grandiosidade brasileira, o samba-exaltação também deveria ser o produto principal de exportação musical (Napolitano, Wasserman, 2000; Paranhos, 2003; Furtado Filho, 2009; Farias, 2014).

Retomando a discussão sobre a questão da criação da obra musical, partimos do pressuposto de que são múltiplos e complexos os motivos que inspiram os compositores no processo de suas criações. Múltiplas e complexas também são as formas de realização social dessas criações musicais no processo de interação entre o compositor e seus interlocutores. Assim, fazendo uma analogia entre a concepção bakhtiniana de "enunciação" (Bakhtin, 1999, p.121) e a criação musical, no caso o samba-exaltação "Sinfonia do café", diríamos que essa composição foi um produto da interação social entre os seus locutores (Humberto Teixeira, Lirio Pannicali, Deo, Coro dos Apiacás e a Orquestra Napoleão e seus Soldados) e seus interlocutores, quer se trate de um ato determinado por situações imediatas e pessoais ou pelo contexto histórico e social mais amplo, no caso, o Estado Novo.

A canção "Sinfonia do café", registrada no selo do disco 78rpm com a indicação "Fantasia em ritmo de samba", enquadra-se no gênero musical samba-exaltação. Suas características observáveis tanto na letra como na melodia remetem a este gênero musical. A letra aborda temática de cunho patriótico-nacionalista, enfatiza a beleza e a grandiosidade dos recursos naturais e humanos e supervaloriza fatos e personagens da história do país. A melodia é sofisticada, com ênfase musical no arranjo orquestral e valorização de recursos sinfônicos. O próprio termo "sinfonia", usado no título da canção, em seu sentido vernáculo, remete ao gênero musical do repertório da orquestra e à vinculação com o teatro musicado, importantes aspectos já comentados.

A letra de "Sinfonia do café" também remete à sua proximidade com o gênero sambaenredo. No enredo de seu samba, o compositor Humberto Teixeira conta em versos musicais a história (saga) do café, desde a sua lendária origem, propagação como hábito alimentar humano, chegada ao país e transformação em principal mercadoria de exportação do Brasil. Eis a letra: 
Vem dos montes abexins ou do Iêmen...

Das lendas de Omar ou do pastor...

Floresceu em terras várias e distantes,

Mas aqui, somente aqui, conheceu o esplendor! ${ }^{4}$

Bonito de ver!

Que lindo de ver, que orgulho de olhar!

$\mathrm{O}$ homem bendiz

A terra onde brota a riqueza sem par!

E canta feliz,

Nos meses de abril,

fazendo a "derriça"

Colhendo os rubis do Café do Brasil!

Café que nasce até nas serras

E viceja nas terras

Onde dão a copaíba e o jacarandá!

Café que fez a glória de Palheta,

$\mathrm{O}$ valoroso bandeirante que nos trouxe

De bem longe,

O ouro-verde para o Grão-Pará!

Café que todo mundo ${ }^{5}$ bebe!

Ó fonte de riquezas mil!

Café que fez famosa a Pauliceia

E espalhou aos quatro ventos

E através dos sete mares

A grandeza do nosso Brasil!

Do nosso Brasil! ${ }^{6}$ (Teixeira, 2002).

Na sequência, vamos tentar realizar a releitura de "Sinfonia do café", procurando com nosso olhar contemporâneo analisar cada parte da letra. Na introdução (primeira estrofe) da canção, Humberto Teixeira se reporta à origem milenar e lendária do cultivo do café, sua incorporação aos hábitos alimentares da sociedade humana e prenuncia o apogeu do ciclo econômico do café no Brasil:

Vem dos montes abexins ou do Iêmen...

Das lendas de Omar ou do pastor...

Floresceu em terras várias e distantes,

Mas aqui, somente aqui, conheceu o esplendor! (Teixeira, 2002).

Assim como ainda fazem os atuais compositores de samba-enredo e, principalmente, os atuais carnavalescos das escolas de samba (Cavalcanti, 2006), parece-nos que Humberto Teixeira realizou importante pesquisa histórica sobre o tema central da canção. Na tentativa de confrontar a fidelidade das informações contidas nos versos dessa primeira estrofe, realizamos breve revisão bibliográfica sobre o hábito de beber café e sua chegada ao Brasil. Na vasta literatura sobre a origem do hábito de beber café, há evidência de que se trata de um costume alimentar milenar. Os manuscritos mais antigos sobre o consumo de café in natura datam de 
575 , sendo encontrados no Iêmen. A lenda sobre a origem do café mais popular é aquela do pastor Kaldi, que há mais de mil anos, na Etiópia, no continente africano, observou que suas cabras, ao comerem os frutos de plantas existentes na região, ficavam alegres e saltitantes. Até o século XVII, apenas os povos árabes plantavam e tinham completo domínio sobre a preparação da bebida café. A circulação da mercadoria café no continente europeu começou por volta de 1615. Os holandeses foram os primeiros a conseguir mudas da planta para cultivo, por volta de 1700, seguidos dos franceses. O crescimento do consumo de café no continente europeu propiciou a expansão de plantações tanto nos países africanos como nas colônias europeias e países das Américas, chegando ao Brasil na terceira década do século XVIII (Lemps, 1998; Barth, 2009; A semente..., 2010; Martins, 2012). Observa-se, portanto, que a literatura consultada corrobora o conteúdo inicial dos primeiros versos da "Sinfonia do café".

Entretanto, de acordo com a literatura sobre a trajetória do café no Brasil, somente a partir de 1840 é que ele passa a ser o principal produto de exportação brasileiro, consolidando o ciclo econômico do café. No início do século XX, esse produto correspondia a cerca de $70 \%$ do volume global das exportações brasileiras, o estado de São Paulo comercializava metade do café mundial, e o Brasil era o maior produtor e exportador mundial de café. As crises cíclicas no processo de produção, comercialização e consumo do café começaram a aparecer desde final do século XIX, acentuando-se entre 1920-1930. Entre as medidas da política estatal de valorização do café, destacaram-se as queimas do estoque ordenadas pelo governo Vargas. Relata-se que entre 1931 e 1944 (ano da criação da "Sinfonia do café") foram queimadas 78.214.000 sacas de café, na tentativa de proteção dos preços do mercado (Alencar, Ramalho, Ribeiro, 1996; Barth, 2009; Tessari, 2014).

Depreende-se, portanto, a fidelidade do compositor em procurar retratar as origens lendárias e românticas do café, mas à medida que busca inspiração em elementos ideológicos de cunho ufanista - "mas aqui, somente aqui, conheceu o esplendor", parece ser infiel na delimitação do contexto de gravação do seu samba. Os versos usados procuram enfatizar a grandiosidade da economia cafeeira, sem qualquer referência às possíveis tensões sociais geradas pelas crises conjunturais de produção e comercialização do café, relatadas desde finais do século XIX e que permaneciam no contexto de criação da canção.

Nos versos seguintes da "Sinfonia do café", Humberto Teixeira faz uma ode aos cafezais, ao processo de colheita do café:

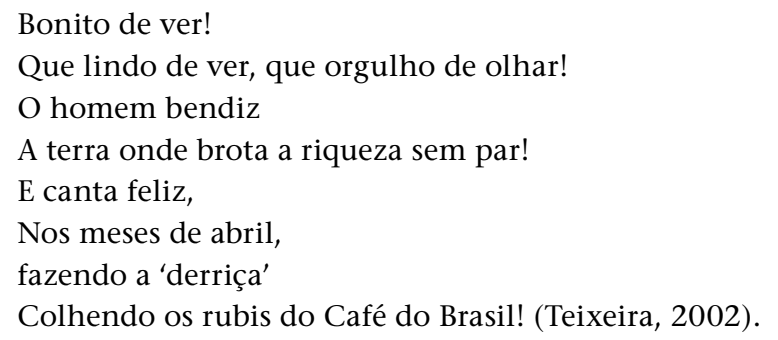

Observa-se que esses versos são muito característicos do gênero musical samba-exaltação e, por extrapolação, da ideologia nacionalista que a política cultural do DIP difundia e recomendava ao longo do Estado Novo (Alencar, Ramalho, Ribeiro, 1996; Paranhos, 2003; Cunha, 2004; Fenerick, 2005; Furtado Filho, 2009). 
Decerto, a beleza dos cafezais e do processo de colheita deve ser intensa e encantadora! No entanto, o lirismo dos versos faz esquecer as contradições do processo de exploração do trabalho humano nos cafezais, atestadas por distintos estudiosos que investigaram esse tema (Lamounier, 2007; Mendes, 2009; Tessari, 2014; Marquese, 2015).

Paradoxalmente, as canções que serão compostas a partir de $1945,{ }^{7}$ principalmente aquelas em parceria com Luiz Gonzaga, apresentam um conteúdo crítico-social sobre as condições de vida e miséria do povo sertanejo nordestino bem distinto do conteúdo de cunho nacionalista-ufanista das canções "Sinfonia do café", "Terra da luz" e "Pelo Brasil, pela vitória". O próprio Humberto Teixeira nos dá as pistas das mudanças de direção dos conteúdos de suas canções:

O Luiz [Gonzaga] dizia que a nossa música foi o primeiro ensaio de música de protesto. ${ }^{8}$ Só que nós fazíamos um tipo de protesto lírico. Eu usava o retirante, a seca, a penúria do Nordeste para chamar a atenção dos nossos irmãos do Sul, bem mais privilegiados, para botar um olhar de ternura, lá para aquelas terras abandonadas (O homem..., 2008).

Assim, em "Asa branca", composta em 1947 em parceria com Luiz Gonzaga, o olhar do compositor, em vez de expressar o orgulho de ver a beleza e grandeza dos cafezais do Sudeste do país, procura retratar um sentimento de tristeza e indignação ao ver o cenário de seca do Nordeste. Vejamos apenas a primeira estrofe de "Asa branca", quando o compositor, usando uma métrica popular, expressa seu protesto lírico:

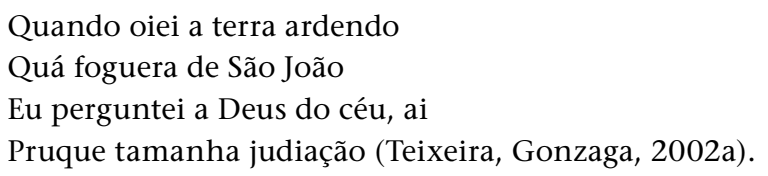

De forma análoga, em "Assum preto", gravada originalmente em 1950 pelo parceiro Luiz Gonzaga, a referência ao mês de abril no cenário do Nordeste é tão lírica quanto distinta daquela dos meses de abril nos cafezais do Sudeste:

Tudo em vorta é só beleza

Sol de abril e a mata em frô

Mas Assum preto, cego dos óio

Num vendo a luz, ai, canta de dô (Teixeira, Gonzaga, 2002b).

Portanto, a parceria com Luiz Gonzaga parece corresponder a um importante momento de ruptura na trajetória musical de Humberto Teixeira. Como vimos, a dupla tem sido reconhecida como a principal propagadora do baião - gênero musical com melodia e letra bem distintas daquelas que caracterizaram o gênero samba-exaltação. $O$ baião recuperava ritmos musicais nordestinos utilizando, basicamente, instrumentos como sanfona (acordeão), zabumba e triângulo em sua composição musical. Em suas letras, versos usando linguagem popular, coloquial, telúrica, sertaneja, camponesa, nostálgica, melancólica, mas também festiva, alegre, extasiante, ressaltando elementos do cotidiano, das paisagens, do solo, do clima, da cultura, do homem nordestino. Acrescenta-se ainda o estilo performático dos seus intérpretes, com indumentárias (chapéu, gibão e sandália de couro), gestos e movimentos bem típicos (Marcondes, 1977; Tinhorão, 2013; Côrtes, 2014; 
Sobral, 2015). Sendo assim, com a propagação do baião essa dupla de artistas recuperava suas origens e raízes geográficas e socioculturais, usando um estilo de "interação musical" com muito mais proximidade e identificação com as camadas populares. A partir da gravação das canções "Baião" (1946) e "No meu pé de serra" (1946), compostas pela dupla, o baião passou a ser um gênero musical reconhecido tanto no Brasil como no exterior. De acordo com algumas análises, foi o gênero musical da moda dos anos 1950 até meados dos anos 1960, sendo amplamente divulgado nos distintos meios de comunicação - rádio, disco, teatro musicado, cinema e televisão (Marcondes, 1977; Tinhorão, 2013). O samba-exaltação foi o gênero musical que possibilitou a visibilidade da música brasileira no exterior no decorrer do Estado Novo, sobretudo com o sucesso de "Aquarela do Brasil". Na década de 1950, entretanto, o baião parece ter possibilitado visibilidade bem mais ampla da música brasileira no exterior, fazendo parte do repertório de vários artistas, orquestras e trilha sonora de filmes estrangeiros (O homem..., 2008; Furtado Filho, 2009; Tinhorão, 2013).

Outros elementos também devem ser elencados na análise sobre a ruptura da trajetória musical do compositor ou, mais precisamente, na mudança de temas, significações e enunciações verificada na complexa relação intersubjetiva entre locutor e interlocutor (Bakhtin, 1999). No nível de determinações mais amplas, tais elementos podem ser buscados nas mudanças do contexto sócio-histórico e político tanto nacional (a queda do Estado Novo) como internacional (o fim da Segunda Guerra Mundial), eventos ocorridos em 1945 (Alencar, Ramalho, Ribeiro, 1996). No nível de determinações econômicas, é preciso analisar possíveis conflitos de interesses da indústria fonográfica (disco, gravadoras) em busca de ampliação de mercado, bem como dos setores vinculados à radiodifusão (Paranhos, 2003; Furtado Filho, 2009; Tinhorão, 2013).

Voltando à leitura de "Sinfonia do café", as condições geográficas favoráveis à expansão da agricultura cafeeira no Brasil foram retratadas por Humberto Teixeira nos seguintes versos:

\author{
Café que nasce até nas serras \\ E viceja nas terras \\ Onde dão a copaíba e o jacarandá! (Teixeira, 2002).
}

Nesses versos, observa-se uma possível alusão do compositor à terra na qual teve início a plantação do café no Brasil - a região amazônica, Pará, onde a árvore copaíba ocorre naturalmente, bem como às terras nas quais o cultivo do café se expandiu e consolidou - a região de São Paulo e Minas Gerais, locais de ocorrência da árvore jacarandá. Nos relatos históricos sobre a rota do café no Brasil, até que ele encontrasse as condições ideais de aclimatação e chegasse ao esplendor de produtividade, ocorreram tentativas em Maranhão, Ceará, Alagoas, Pernambuco, Paraíba, Bahia, Goiás e Rio de Janeiro. Com a chegada ao vale do rio Paraíba, no início do século XIX, verifica-se a emergência do ciclo econômico do café brasileiro. A partir de então, a agricultura cafeeira espalhou-se pelas matas, vales, serras e montanhas da região, propiciando o surgimento e o crescimento de cidades nos estados de São Paulo, Minas Gerais e Paraná. A agricultura cafeeira possibilitou a construção de ferrovias e portos para o escoamento da produção; impulsionou o comércio inter-regional; propiciou o intenso processo de imigração estrangeira e de migração 
interna, particularmente dos habitantes da região Nordeste para a região Sudeste do país; estimulou o processo de urbanização e industrialização; consolidou a expansão da classe média, a diversificação de investimentos e até mesmo intensificou movimentos culturais. Em detrimento às benesses que a agricultura cafeeira possibilitou, o samba-exaltação de Humberto Teixeira omite referências ao processo predatório de desmatamento de matas e florestas para extração de madeira, particularmente do jacarandá, ocorrido sobretudo na primeira metade do século XX (Alencar, Ramalho, Ribeiro, 1996; Young, 2006; Barth, 2009; A semente..., 2010; Martins, 2012; Tessari, 2014; Silva, 2015).

Na sequência da sua canção, Humberto Teixeira apresenta os versos que referendam a versão da história sobre a introdução do cultivo do café no Brasil:

Café que fez a glória de Palheta,

$\mathrm{O}$ valoroso bandeirante que nos trouxe

De bem longe,

O ouro-verde para o Grão-Pará! (Teixeira, 2002).

De fato, em conformidade com a literatura investigada, a introdução do plantio do café no Brasil (espécie Coffea arabica) tem sido atribuída ao sargento-mor Francisco de Melo Palheta (1670-c.1750). Em 1727, em missão designada pelo governador do Maranhão e Grão-Pará, Palheta teria trazido de Caiena, capital da Guiana Francesa, as primeiras mudas de café que seriam plantadas em suas sesmarias, em Vigia, província do Grão-Pará, onde chegou a possuir mais de mil pés dessa planta (Barth, 2009; A semente..., 2010; Martins, 2012).

Nos versos seguintes de "Sinfonia do café", Humberto Teixeira faz alusão ao hábito alimentar de beber café, identificando-o como uma prática alimentar universal. Na sequência, faz apologia às suas possíveis benesses:

Café que todo mundo bebe!

Ó fonte de riquezas mil! (Teixeira, 2002).

Tomando como parâmetro de análise a interação verbal intersubjetiva entre locutor e interlocutor (Bakhtin, 1999), poderíamos tentar identificar os possíveis significados que esses versos da "Sinfonia do café" estariam exprimindo sobre o hábito de beber café, naquele contexto de idealização da canção, tanto no âmbito mundial como no Brasil. Decerto, o caráter polissêmico dos versos "Café que todo mundo bebe, ó fonte de riquezas mil" pode encerrar vários significados além do seu sentido original, conforme idealizado pelo seu locutor, naquele contexto de meados dos anos 1940. Em primeiro lugar, o significado mais aparente e evidenciado pela canção parece ser aquele relacionado ao campo econômico: o café como mercadoria, fonte de riqueza monetária. Em segundo lugar, um significado intermediário ou pouco enfatizado nesses versos parece estar relacionado ao campo sociossimbólico, o café como hábito alimentar universal e, em particular, da população brasileira. Em terceiro lugar, um significado oculto ou omitido por esses versos parece estar relacionado ao campo nutricional - o café como fonte de nutrientes e outros princípios bioativos que podem acarretar benefícios e/ou riscos à saúde.

Na última estrofe da canção aparece a exaltação ao pretenso poder político, econômico e ideológico da mercadoria café: 


\section{Café que fez famosa a Pauliceia \\ E espalhou aos quatro ventos \\ E através dos sete mares \\ A grandeza do nosso Brasil! \\ Do nosso Brasil! (Teixeira, 2002).}

O uso do nome "Pauliceia" para retratar a cidade ou o estado de São Paulo talvez seja uma referência à obra Pauliceia desvairada, de Mário de Andrade (1893-1945), publicada em 1922, ano da Semana de Arte Moderna (Andrade, 2016). Mas, de fato, atribuiu-se ao café o papel de motor do desenvolvimento econômico e social do estado de São Paulo a partir de então (A semente..., 2010; Martins, 2012; Silva, 2015).

Sendo assim, dentro da perspectiva nacionalista/ufanista concebida pelo Estado Novo, a canção se encerra evocando a grandeza do país, disseminada pelo mundo a partir da exportação do café brasileiro.

\section{Considerações finais}

A perspectiva sócio-histórica adotada buscou explorar as relações entre a obra musical ("Sinfonia do café"), a trajetória de seu autor, Humberto Teixeira, e o contexto de sua criação. Nesse sentido, resguardadas as especificidades e distinções, conserva semelhança com outras investigações que também se fundamentaram em abordagens contextuais, tais como o estudo de Costa (2015), que analisou o processo de criação do gênero musical carimbó entre os anos 1900-1960, já comentado anteriormente; e o estudo de Garcia (2011), que analisou duas canções da banda de rock britânica The Beatles, "Strawberry fields forever" e "Penny Lane", lançadas em 1967, com o objetivo de compreender como tais composições musicais participaram da construção e da negociação de identidades que definiram vínculos e fronteiras no tecido urbano, ao mesmo tempo que evidenciaram as trajetórias traçadas pelos músicos que o atravessaram.

A análise da letra de "Sinfonia do café" fundamentada na filosofia bakhtiniana da linguagem, em particular suas concepções de "enunciação" e "interação verbal", assemelha-se a outros estudos que realizaram abordagens linguísticas de composições musicais, tais como o estudo de Freitas e Facin (2012), já comentado anteriormente, que se fundamentou na "teoria da enunciação" de Émile Benveniste; e o estudo de Mori (2015) que buscou mapear as unidades temáticas de ciência e tecnologia em três canções ("Lance de dados", "Nem + um dia" e "Luz"), de Humberto Gessinger, músico, cantor e compositor do grupo de rock brasileiro Engenheiros do Hawaii. Mori (2015) centralizou sua análise linguística no conceito de "enunciado" da filosofia da linguagem bakhtiniana, tendo como instrumental metodológico a técnica de análise de conteúdo descrita por Laurence Bardin (2008).

Um dos eixos do estudo procurou investigar a relação intersubjetiva entre locutor e interlocutor, buscando identificar possíveis significações da canção e do tema central abordado (café) no contexto de sua criação. A análise da letra de "Sinfonia do café" permitiu identificar pelo menos três níveis de significação: nível imediato - significado econômico; nível intermediário - significado sociossimbólico; e nível oculto - significado nutricional. 
Em relação ao significado econômico, ressalta-se que há quase dois séculos o café tem sido considerado uma das mais importantes mercadorias do comércio internacional. A produção mundial do café é liderada pelo Brasil desde a década de 1850. Em 2016-2017, o Brasil mantém-se como o maior produtor e exportador mundial de café, sendo responsável por 30\% do mercado internacional. Nesses anos, constitui o segundo mercado consumidor de café (ICO, s.d.-a, s.d.-b). A literatura investigada aponta que o café constitui uma das bebidas mais consumidas no mundo (Alves, Casal, Oliveira, 2009; Ding et al., 2014; Liu et al., 2016; Wang et al., 2017).

Em relação ao significado sociossimbólico de "Sinfonia do café", conforme Gilberto Freyre (1900-1987), a introdução do hábito de consumir café pela população brasileira foi um fenômeno ocorrido na emergência da economia cafeeira, em meados do século XIX (Freyre, 2000). Em Geografia da fome, publicada pela primeira vez em 1946, Josué de Castro (1908-1973) também relata o hábito de consumir café no Brasil (Castro, 1980). Ao descrever as características da composição da dieta básica do Nordeste açucareiro, ele aponta a origem brasileira do hábito de misturar café com leite, atribuído ao holandês Joan Jacob Nieuhof (1618-1672), quando da passagem pelo Brasil entre 1640 a 1649 (Castro, 1980, p.138). Entretanto, essa versão foi contestada por Luís da Câmara Cascudo (1898-1986) na obra História da alimentação (Cascudo, 2004). Para Câmara Cascudo, Joan Nieuhof teria deixado o Brasil em 1649 e o café só teria chegado ao país em 1727. Além disso, ele relata que desde 1637 registrava-se o hábito de beber a mistura café com leite em Amsterdã, Holanda (Cascudo, 2004, p.368). Ainda segundo Câmara Cascudo, no Brasil, os primeiros registros do hábito de beber café ao final do jantar datam de 1750, inicialmente um costume relacionado aos nobres. De 1760 a 1860, ele relata evidências da expansão do hábito de beber café ao final do jantar e almoço; na primeira refeição matinal; nas capitais das províncias das distintas regiões do país; e entre as diferentes classes sociais. Além disso, ele registra relatos sobre o uso do café como remédio; como bebida "tônica" (energética) oferecida pelos fazendeiros para obtenção de maior rendimento de trabalho dos escravos; bebida recomendada para adultos e proibida para crianças; e também como bebida comercializada por negras ambulantes na capital federal, à época, Rio de Janeiro, no período das 6 às 10 horas da manhã (Cascudo, 2004, p.366-369). Por sua vez, no contexto internacional, o hábito de beber café difundiu-se no final do século XV, no luxo e suntuosidade das cafeterias de Meca. No século XVI, as cafeterias espalharam-se para Constantinopla, Síria, Turquia e Veneza. No século XVII, as cafeterias se difundiram por Viena, Paris, Londres, Berlim, Amsterdã, entre outras cidades, caracterizando-se como locais onde ocorriam encontros ou reuniões comerciais, sociais, políticas, musicais e artísticas das classes privilegiadas em torno de xícaras de café (Lemps, 1998; A semente..., 2010; Martins, 2012).

Em relação ao significado nutricional, oculto na "Sinfonia do café", de acordo com a literatura investigada, a bebida café, solução aquosa sem adição de açúcar, leite ou outro alimento/ingrediente, é praticamente destituída de valor calórico, sendo uma boa fonte alimentar de ácidos clorogênicos, cafeína, diterpenos, niacina (vitamina B3), minerais (cálcio, ferro, magnésio, potássio, sódio, zinco entre outros) e traços de aminoácidos. Em função dos seus significados econômicos e sociais, os estudos dos potenciais efeitos do café sobre a saúde são abundantes e muito antigos. Na época de criação da "Sinfonia do café" 
prevaleciam os estudos científicos focados nos efeitos estimulantes da cafeína, com ênfase nos possíveis riscos à saúde. No contexto atual, os resultados de pesquisas epidemiológicas têm apontado mais benefícios do que malefícios do consumo de café para a saúde humana. Os estudos têm sugerido que o consumo frequente e moderado de café (três a quatro xícaras/ dia) pode ajudar a prevenir várias doenças crônicas não transmissíveis, incluindo diabetes mellitus tipo 2, doença de Parkinson e doença hepática. A maioria dos estudos não tem encontrado associação entre consumo de café e aumento do risco de doença cardiovascular. Embora tenha sido observado que o consumo de café está associado a fatores de risco de doenças cardiovasculares, tais como pressão arterial e homocisteína plasmática. Há pouca evidência entre o consumo de café e o aumento do risco de vários tipos de câncer. Evidências sugerem consumo moderado de café para alguns grupos populacionais, incluindo gestantes, pessoas com hipertensão, crianças, adolescentes e idosos, em função de potencial vulnerabilidade aos efeitos adversos da cafeína (Alves, Casal, Oliveira, 2009; Lima et al., 2010; Ding et al., 2014; Liu et al., 2016; Wang et al., 2017).

Em síntese, a releitura de "Sinfonia do café" remete à identificação do possível significado político-ideológico que o gênero de canção samba-exaltação exprimiu no contexto de sua criação. "Sinfonia do café" sintetiza a concretização da política cultural-ideológica que o Estado Novo ousou projetar para o Brasil e para o mundo, procurando difundir uma imagem de grandiosidade e opulência a partir de dois produtos nacionais de exportação (agrícola e cultural), samba e café.

\section{NOTAS}

${ }^{1}$ Referências apontam que teria sido Lauro Maia o criador do balanceio, misturando ritmos típicos do Nordeste com a marchinha carioca. A canção "A marcha do balanceio", de Lauro Maia e Humberto Teixeira, gravada para o carnaval de 1946, é apontada como exemplificação desse ritmo, além de revelar semelhança com o baião (Tinhorão, 2013; ICCA, s.d.-a).

${ }^{2}$ Entre as mais de quatrocentas composições de Humberto Teixeira destacam-se: "A marcha do balanceio" (1946), "Asa branca" (1947), "Assum preto" (1950), "Adeus, Maria Fulô" (1974), "Baião" (1946), "Baião de dois" (1950), "Bodocongó" (1966), "Deus me perdoe" (1945), "Dezessete léguas e meia" (1949), "Dono dos teus olhos" (1956), "Estrada de Canindé" (1950), "Juazeiro" (1949), "Kalu" (1952), "Légua tirana" (1949), "Mangaratiba" (1949), "No meu pé de serra" (1946), "Orélia" (1979), "Paraíba" (1950), “Qui nem jiló" (1950), "Respeita Januário" (1950), “Sinfonia do café" (1944) e "Xanduzinha” (1950).

${ }^{3}$ Entre os artistas que gravaram composições de Humberto Teixeira, apontamos: Ângela Maria, Araci de Almeida, Alceu Valença, Bebel Gilberto, Carmélia Alves, Caetano Veloso, Carmen Miranda, Chico Buarque, Chico César, Chitãozinho e Xororó, Claudete Soares, Clara Nunes, Cyro Monteiro, Cordel do Fogo Encantado, Dalva de Oliveira, Dominguinhos, Elba Ramalho, Ednardo, Elis Regina, Fagner, Gal Costa, Geraldo Vandré, Gilberto Gil, Gonzaguinha, Hermeto Pascoal, Jackson do Pandeiro, Joyce, Lenine, Lucy Alves, Lulu Santos, Maria Alcina, Maria Bethânia, Miriam Makeba, Ney Matogrosso, Os Mutantes, Orlando Silva, Quinteto Violado, Raul Seixas, Rita Ribeiro, Sivuca, Tom Zé, Zé Ramalho e Zeca Pagodinho.

${ }^{4} \mathrm{Na}$ regravação de "Sinfonia do café" (Teixeira, 2002), Rita Ribeiro omitiu essa primeira estrofe da letra da canção, que aparece na gravação original (O homem..., 2008).

${ }^{5} \mathrm{Na}$ letra da primeira gravação de "Sinfonia do café" aparece nesta estrofe: "O mundo inteiro bebe" (O homem..., 2008).

${ }^{6} \mathrm{Na}$ regravação de "Sinfonia do café" (Teixeira, 2002), Rita Ribeiro também omitiu a repetição da expressão "Do nosso Brasil" que encerrava a canção na gravação original.

${ }^{7}$ É preciso ressaltar que em 1945 foi gravada por Deo e Coro dos Apiacás, com acompanhamento da orquestra Napoleão e seus Soldados Musicais, a canção "Terra da luz", composição de Humberto Teixeira (1945). A 
letra dessa canção também pode ser enquadrada no gênero samba-exaltação, na qual o compositor procura exaltar as belezas e grandiosidades de seu estado natal, o Ceará. Essa canção participou de um festival de música, sendo classificada em primeiro lugar, enquanto sua principal concorrente, "Terra seca", de autoria de Ary Barroso, que também se enquadra no gênero samba-exaltação, ficou em segundo lugar (Barroso, 1944; Teixeira, 1945; O homem..., 2008; Programa Perfil, 2015).

${ }^{8}$ Sobre a temática "canção de protesto", ver, entre outros, Contier (1998); Napolitano (2010); Vasconcelos, Vasconcelos, Vasconcelos (2015).

\section{REFERÊNCIAS}

ALENCAR, Francisco; RAMALHO, Lúcia Carpi; RIBEIRO, Marcus Venício T.

História da sociedade brasileira. Rio de Janeiro: Ao Livro Técnico. 1996.

ALVES, Rita C.; CASAL, Susana; OLIVEIRA, Beatriz. Benefícios do café na saúde: mito ou realidade? Química Nova, v.32, n.8, p.2.169-2.180. 2009.

\section{ANDRADE, Mario.}

Pauliceia desvairada. São Paulo: Ciranda Cultural. 2016.

\section{A SEMENTE...}

A semente do ouro negro. Direção: Carlos

Barreto. Portugal: Happygénio. 50 min. 2010.

Disponível em: <https://www.youtube.com/ watch?v=VvpBdUUMUHU>. Acesso em: 27 nov. 2016. 2010.

ASSIS, Carlos Alberto.

Fatores de coerência nos "Choros no 5 (Alma brasileira)", de Heitor Villa-Lobos. Per Musi, n.20, p.64-73. 2009.

\section{BAKHTIN, Mikhail.}

Marxismo e filosofia da linguagem: problemas fundamentais do método sociológico na ciência da linguagem. São Paulo: Hucitec. 1999.

BARALDI, Filippo Bonini.

Como estudar a emoção musical? Propostas metodológicas a partir de pesquisa junto aos ciganos da Transilvânia (Romênia). Sociologia \& Antropologia, v.6, n.3, p.699-734. 2016.

BARDIN, Laurence.

Análise de conteúdo. Lisboa: Edições 70. 2008.

BARROSO, Ary.

Terra seca. Intérprete: Deo e Coro dos Apiacás com acompanhamento da orquestra Napoleão Tavares e seus Soldados Musicais. Rio de Janeiro: Continental. Disco 78 rpm. Lado A e B. 5,28 min. [canção]. Disponível em: <https://www. youtube.com/watch?v=TZH3GUN20Sw>. Acesso em: 9 mar. 2018. 1944.

BARTH, Glauce Maris Pereira.

A leitura do café: suas possíveis relações matemáticas e a perspectiva de gênero. Educar em Revista, n.35, p.153-164. 2009.
BRILHANTE, Aline Veras Morais; NATIONS, Marilyn Kay; CATRIB, Ana Maria Fontenelle. "Taca cachaça que ela libera": violência de gênero nas letras e festas de forró no Nordeste do Brasil. Cadernos de Saúde Pública, v.34, n.3, p.e00009317. 2018.

CASCUDO, Luís da Câmara.

História da alimentação no Brasil. São Paulo: Global. 2004.

CASTRO, Josué de.

Geografia da fome (o dilema brasileiro: pão ou aço). Rio de Janeiro: Antares/Achiamé. 1980.

CAVALCANTI, Maria Laura Viveiros de Castro. As alegorias no carnaval carioca: visualidade espetacular e narrativa ritual. Textos Escolhidos de Cultura e Arte Populares, v.3, n.1, p.17-27. 2006.

CONTIER, Arnaldo Daraya.

Edu Lobo e Carlos Lyra: o nacional e o popular na canção de protesto (os anos 60). Revista Brasileira de História, v.18, n.35, p.13-52. 1998.

CÔRTES, Almir.

Como se toca o baião: combinações de elementos musicais no repertório de Luiz Gonzaga. Per Musi, n.29, p.195-208. 2014.

COSTA, Antonio Maurício Dias.

A produção da "música cabocla": a polifonia formadora do carimbó nas representações de literatos, jornalistas e folcloristas no Pará (19001960). História, v.34, n.1, p.241-273. 2015.

CUNHA, Fabiana Lopes da.

Da marginalidade ao estrelato: O samba na construção da nacionalidade (1917-1945). São Paulo: Annablume. 2004.

DING, Ming et al.

Long-term coffee consumption and risk of cardiovascular disease: a systematic review and a dose-response meta-analysis of prospective cohort studies. Circulation, v.129, n.6, p.643-659. 2014.

ERNICA, Mauricio; MOLINA, Sergio.

A sagração da Portela: música, letra e contexto social na produção de reações estéticas em um samba-enredo. Per Musi, n.34, p.177-205. 2016. 
FAGUNDES, Luciana Pessanha.

Música e guerra: impactos da Primeira Guerra Mundial no cenário musical carioca. Revista Brasileira de História, v.37, n.76, p.23-44. 2017.

FALBO, Conrado Vitor Rodrigues.

A palavra em movimento: algumas perspectivas teóricas para a análise de canções no âmbito da música popular. Per Musi, n.22, p.218-231. 2010.

FARIAS, George Manoel.

Convenções e invenções em torno da tópica 5 - \#5 - 6 no processo musical nacionalista no Brasil. Per Musi, n.29, p.147-153. 2014.

FENERICK, José Adriano.

Nem do morro nem da cidade: as transformações do samba e a indústria cultural, 1920-1945. São Paulo: Annablume; Fapesp. 2005.

FGV.

Fundação Getulio Vargas. Centro de Pesquisa de História Contemporânea do Brasil. Humberto Cavalcanti Teixeira. In: Dicionário Histórico Biográfico Brasileiro pós-1930. Rio de Janeiro: FGV. (verbete). Disponível em: <http://www.fgv.br/ cpdoc/acervo/dicionarios/verbete-biografico/ humberto-cavalcanti-teixeira>. Acesso em: 24 nov. 2016. 2001.

FREITAS, Ernani Cesar; FACIN, Débora. Análise enunciativa de "Canto para minha morte", de Raul Seixas. Linguagem em (Dis)curso, v.12, n.2, p.573-593. 2012.

FREYRE, Gilberto.

Sobrados e mucambos. Rio de Janeiro: Record. 2000.

FURTADO FILHO, João Ernani.

Samba exaltação: fantasia de um Brasil brasileiro. Trajetos, v.7, n.13, p.129-167. 2009.

GARCIA, Luiz Henrique Assis.

Em meus olhos e ouvidos: música popular, deslocamento no espaço urbano e a produção de sentidos em lugares dos Beatles. Estudos históricos, v.24, n.47, p.99-118. 2011.

ICCA.

Instituto Cultural Cravo Albin. Dicionário Cravo Albin da Música Popular Brasileira. Lauro Maia. (verbete). Disponível em: <http:// dicionariompb.com.br/lauro-maia/dadosartisticos>. Acesso em: 8 mar. 2018. s.d.-a.

ICCA.

Instituto Cultural Cravo Albin. Dicionário Cravo Albin da Música Popular Brasileira. Humberto Teixeira. (verbete). Disponível em: <http://www. dicionariompb.com.br/humberto-teixeira/dadosartisticos>. Acesso em: 25 nov. 2016. s.d.-b.

ICO.

International Coffee Organization. Historical data on the global coffee trade: total production by all exporting countries (In thousand $60 \mathrm{~kg}$ bags). Disponível em: <http://www.ico.org/ historical/1990\%20onwards/PDF/1a-totalproduction.pdf $>$. Acesso em: 4 jun. 2017. s.d.-a.

ICO.

International Coffee Organization. Historical data on the global coffee trade: total production by all exporting countries (In thousand $60 \mathrm{~kg}$ bags). Disponível em: <http://www.ico.org/prices/ new-consumption-table.pdf $>$. Acesso em: 4 jun. 2017. s.d.-b.

LAMOUNIER, Maria Lúcia.

Agricultura e mercado de trabalho:

trabalhadores brasileiros livres nas fazendas de café e na construção de ferrovias em São Paulo, 1850-1890. Estudos Econômicos, v.37, n.2, p.353372. 2007.

LEMPS, Alain Huertz.

As bebidas coloniais e a rápida expansão do açúcar. In: Flandrin, Jean-Louis; Montanari, Massimo. História da alimentação. São Paulo: Estação Liberdade. p.611-624. 1998.

LIMA, Fabiana Accioly de et al.

Café e saúde humana: um enfoque nas substâncias presentes na bebida relacionadas às doenças cardiovasculares. Revista de Nutrição, v.23, n.6, p.1.063-1.073. 2010.

LIU, Quing-Ping et al.

Habitual coffee consumption and risk of cognitive decline/dementia: a systematic review and meta-analysis of prospective cohort studies. Nutrition, v.32, n.6, p.628-636. 2016.

MARCONDES, Marcos Antonio (Ed.).

Enciclopédia da música brasileira: erudita, folclórica e popular. São Paulo: Art Editora. 2v. 1977.

MARQUESE, Rafael de Bivar.

As origens de Brasil e Java: trabalho compulsório e a reconfiguração da economia mundial do café na Era das Revoluções, c.1760-1840. História, v.34, n.2, p.108-127. 2015.

MARTINS, Ana Luiza.

História do café. São Paulo: Contexto. 2012.

MENDES, José Sacchetta Ramos.

Desígnios da Lei de Terras: imigração, escravismo e propriedade fundiária no Brasil Império. Caderno CRH, v.22, n.55, p.173-184. 2009.

MORI, Rafael Cava.

Sentir com a inteligência, pensar com a emoção: ciência e tecnologia em canções de Humberto Gessinger. História, Ciências, Saúde - Manguinhos, v.22, n.3, p.743-760. 2015. 
MOTTA, Ana Raquel.

O papel da música nas atividades de trabalho. Bakhtiniana, Revista de Estudos do Discurso, v.10, n.2, p.90-114. 2015.

NAPOLITANO, Marcos.

MPB: a trilha sonora da abertura política (19751982). Estudos Avançados, v.24, n.69, p.389-402. 2010.

\section{NAPOLITANO, Marcos; WASSERMAN, Maria}

Clara.

Desde que o samba é samba: a questão das origens no debate historiográfico sobre a música popular brasileira. Revista Brasileira de História, v.20, n.39, p.167-189. 2000.

NOLETO, Rafael da Silva.

Eu sou uma fruta "gogoia", eu sou uma moça: Gal Costa e o tropicalismo no feminino. Per Musi, n.30, p.64-75. 2014.

\section{O HOMEM...}

O homem que engarrafava nuvens. Direção: Lírio Ferreira. Rio de Janeiro: Good Ju-Ju Productions/ Total Entertrainment/Asylum Films. $107 \mathrm{~min}$. Disponível em: <https://www.youtube.com/ watch?v=OLLcf8UTnPo $>$. Acesso em: 27 nov. 2016. 2008.

PARANHOS, Adalberto.

A invenção do Brasil como terra do samba: os sambistas e sua afirmação social. História, v.22, n.1, p.81-113. 2003.

PROGRAMA PERFIL.

Humberto Teixeira: vida e música. Direção: Ângela Gurgel. Fortaleza: TV Assembleia Legislativa do Ceará. 44,02 min. (documentário). Disponível em: <https://www. youtube.com/watch?v=JyKtMjaDlv0>. Acesso em: 8 mar. 2018. 2015.

SILVA, Gustavo Pereira da.

As brechas ao capital nacional: a liderança da casa J.F. de Lacerda \& Cia. sobre a exportação cafeeira em Santos na década de 1880. Economia e Sociedade, v.24, n.3, p.541-571. 2015.

SOBRAL, Moacir Ribeiro Barreto.

Luiz Gonzaga e alimentação sertaneja: as práticas alimentares representadas nas letras musicais. Interações, v.16, n.1, p.155-162. 2015.

TEIXEIRA, Humberto.

Sinfonia do café. Intérprete: Rita Ribeiro. In: Teixeira, Humberto. O doutor do baião. Rio de
Janeiro: Biscoito Fino. 1 CD. Faixa 7. (canção). 2002.

TEIXEIRA, Humberto.

Terra da luz. Intérprete: Deo e Coro dos Apiacás, com acompanhamento da orquestra Napoleão Tavares e seus Soldados Musicais. Rio de Janeiro: Continental. Disco 78 rpm. Lado A e B. 6,03 min. (canção). Disponível em: <https://www. youtube.com/watch?v=n86_byGhNXo $>$. Acesso em: 9 mar. 2018. 1945.

TEIXEIRA, Humberto; GONZAGA, Luiz. Asa branca. Intérprete: Maria Bethânia. In: Teixeira, Humberto. O doutor do baião. Rio de Janeiro: Biscoito Fino. 1 CD. Faixa 1. (canção). 2002a.

TEIXEIRA, Humberto; GONZAGA, Luiz. Assum preto. Intérprete: Elba Ramalho. In: Teixeira, Humberto. O doutor do baião. Rio de Janeiro: Biscoito Fino. 1 CD. Faixa 17. (canção). 2002b.

TESSARI, Cláudia Alessandra.

Trabalhadores temporários para o café:

mecanização e núcleos coloniais em São Paulo, 1895-1911. Estudos Econômicos, v.44, n.2, p.409434. 2014.

TINHORÃO, José Ramos.

Pequena história da música popular segundo seus gêneros. São Paulo: Editora 34. 2013.

VASCONCELOS, Francisco de Assis Guedes de; VASCONCELOS, Mariana Perrelli; VASCONCELOS, Iris Helena Guedes de. Fome, comida e bebida na música popular brasileira: um breve ensaio. História, Ciências, Saúde-Manguinhos, v.22, n.3, p.723-741. 2015.

VIVACQUA, Renato.

Crônica carnavalesca da história: a história cantada e contada pela música carnavalesca. Brasília: Thesaurus. 2004.

WANG, Tiange et al.

Habitual coffee consumption and genetic predisposition to obesity: gene-diet interaction analyses in three US prospective studies. $B M C$ Medicine, v.15, p.97. 2017.

YOUNG, Carlos Eduardo Frickmann.

Desmatamento e desemprego na Mata Atlântica. Floresta e Ambiente, v.13, n.2, p.75-88. 2006.

\section{$\rightarrow \rightarrow \rightarrow<<<$}

